\title{
IN MEMORIAM: \\ Academician \\ Kamil A. Valiev \\ January 15, 1931-July 28, 2010
}

DOI: $10.1134 / \mathrm{S} 1063739710060016$

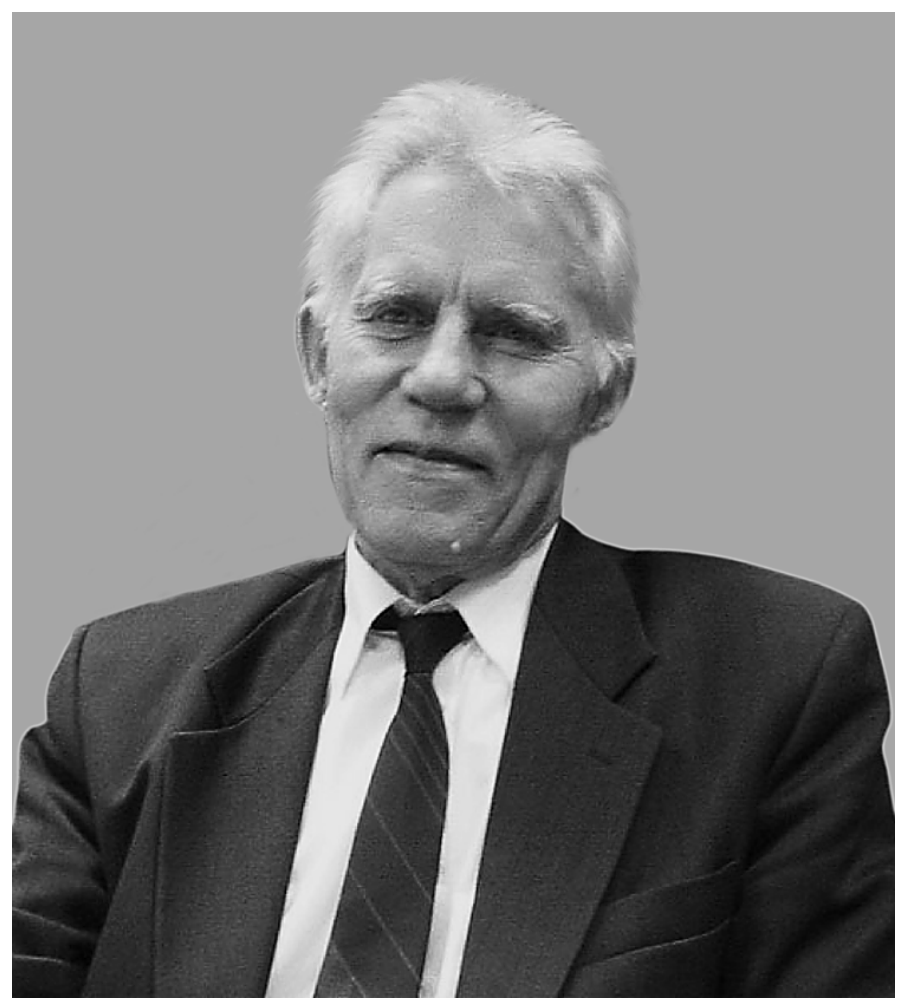

It is with deep sorrow that we have to report the death of Professor Kamil Akhmetovich VALIEV, a full member of the Russian Academy of Sciences. He died on July 28, 2010, after a severe illness in his 80th year. He was a prominent Russian scientist in the fields of condensed-matter physics, micro- and nanoelectronics processing, and quantum computing, whose contributions were recognized by the Lenin Prize and the USSR State Prize. He established and led the Academy's Institute of Physics and Technology, and served as a deputy head of the Academy's Branch of Nanotechnologies and Information Technologies, editor-in-chief of journal "Mikroelektronika".

Bureau of the Branch of Nanotechnologies and Information Technologies, Russian Academy of Sciences 